\title{
Challenges of Financial Risk Management: Al Applications
}

DOI: 10.7595/management.fon.2021.0015

\begin{abstract}
:
Research Question: This paper reviews different artificial intelligence (Al) techniques application in financial risk management. Motivation: Financial technology has significantly changed the business operations which required transformation of financial industry. The financial risk management needs to be restructured because the methods that have been used in the past became low effective. The artificial intelligence techniques proved their efficiency and contributed to fast, low-cost and improved financial risk management in both financial institutions and companies. Idea: The aim of this paper is to present a state of Al techniques application in financial risk management, as well as to point out the direction in which further application and development could be expected. Data: The analysis was conducted by reviewing various papers, books and reports on Al applications in financial risk management. Tools: The relevant literature systematization was used to provide answers to the question to what extent Al techniques (especially machine learning) could be used in managing financial risk management. Findings: Artificial intelligence largely improved the market risk and credit risk management through data preparation, modelling risk, stress testing and model validation. Artificial intelligence techniques can be useful in data quality assurance, text-mining for data augmentation and fraud detection. The financial technology will continue to affect the financial sector through requiring the adaption to new environment and new business models. Because of that, it could be expected that artificial intelligence will become part of the financial risk management framework. Contribution: This paper provides a review of artificial intelligence applications in market risk management, credit risk management and operational risk management. The paper identified the key Al techniques that could be used for financial risk management improvement because of financial industry transformation.
\end{abstract}

Keywords: artificial intelligence, market risk, credit risk, operational risk, machine learning

JEL Classification: C19, C24, G17, G19. G21, G28, O36

\section{Introduction}

It is almost impossible today to manage financial risks without artificial intelligence (Al) techniques. There are a number of reasons for this, but undoubtedly one of the most important is the fact that traditional financial risk management approaches, methods and techniques became costly, time-consuming and insufficient. Namely, the adequate combination of traditional financial risk management and Al approaches can provide basis for effective business application. This can generate more efficiency, confidence and potential for operation and growth in modern turbulent business environment of each participant regardless the industry.

Over the past ten years the challenges and issues that need to be solved can be summarized as: market risk modelling (Day, 2017), evaluation of the so-called "market impact" (i.e., impact of firm's own trading on market prices), validation of market risk management models (Regan et al., 2017), cost reduction through identification of assets in which it would be desirable to take position (Heaton et al., 2017). 
Financial technology (Fintech) development in the period of the last five years has led to a fast development of artificial intelligence techniques that improved the wayin which financial industry operates. The use of different technologies (blockchain, artificial intelligence and big data analytics) has changed the financial industry and has enabled direct and easier access to financial services. Regardless of this, Fintech has introduced many risks that may deteriorate the participants' protection (e.g., market risk incompliance, credit rating underestimation etc.). This led to a disruption of finance, and within this, the need for financial risk management transformation and improvement. Financial risk management will continue to use new technologies so that it can provide efficiency and a more reliable decision-making. In this regard, the use of Al became inevitable for both financial institutions and corporations.

The rest of the paper is structured as follows: in the section two, the relationship between Al and financial risk management is presented. Section three is about the use of Al in market risk management. Section four considers the possibilities of $\mathrm{Al}$ use in credit risk management. The use of $\mathrm{Al}$ in operational risk management is presented in section five. The challenge of $\mathrm{Al}$ in financial risk management is analysed in section six. Finally, concluding remarks and the directions for further research are given in section seven.

\section{Al in Financial Risk Management}

Financial risk management today is in the process of transforming because of the influence of Fintech that led to financial sector disruption. Financial risk management is a practice of optimizing the way financial institutions or corporations can take on financial risk. In broader terms, Al is part of Fintech and it has already changed the mode in which the financial risk is managed. Besides, Al has helped financial risk management by increasing the decision-making efficiency.

As it is already mentioned, Al is broad-field oriented towards the use of different techniques based on humanlike intelligence. These techniques use past experience (e.g., different data sets) in an efficient and intelligent way (mimic to human behaviour). The key Al technique is machine learning that enables data preparation and predictions which can be valuable for financial risk decision-making.

Machine learning types are supervised learning and unsupervised learning. Supervised learning is based on collected data and tries to predict the outcome by using partial least squares, principal component analysis, least absolute shrinkage and selection operator, least angle regression, ridge, decision tress, support vector machine, artificial neural networks and deep learning techniques (van Liebergen, 2017).

All the mentioned techniques can be used in financial risk management. Hence, some techniques are used more often in credit risk management. For example, principal component analysis is commonly used for credit repayment risk determination, credit assessment along with artificial neural networks (Hamdy and Hussein, 2016) but also as an input for neural networks for asset price and stock indices predictions (Wang and Wang, 2015) and equity portfolio management.

In addition, support vector machine learning has been used for default risk predictions (Nazemi et al., 2018), credit scoring (Harris, 2015), credit default prediction (Abedin et al., 2018), credit risk evaluation (Lean, 2014), estimation of Value-at-Risk (Radovic and Stankovic, 2015) etc. A combination of support vector machine with some other machine learning techniques (e.g., neural networks) showed advantages in comparison with traditional ones.

The unsupervised techniques are used for better classification among the data and for the creation of cluster groups enabling to get signals that might be included in decision-making.

Finally, deep learning and neural networks should be viewed as a part of both supervised and unsupervised machine learning because they can be applied to outcome prediction (e.g., level of market or credit risk) as well as to learning from data and providing more reliable indicators for financial risk management. Artificial neural networks are widely used for credit risk prediction (Pacelli and Azzollini, 2011), credit risk evaluation and asset price predictions.

Deep learning combines artificial neural networks with techniques that enable an automatical discovering of the representative data for variable detection and/or to make classification from data. In other words, deep learning uses a hierarchical level of artificial neural networks that enables processing the data using a nonlinear approach. This technique represents a new technique which adds so-called hidden layers (variables) to input data and allows for modelling the influences among them. That way deep learning helps 
solving the problem known as a "black box”. This is of great importance for financial risk management because the "black box" is immanent in financial risk decision-making. Deep learning can be used for estimation of asset pricing models for individual stock returns through combining different deep learning techniques (Chen et al., 2019). Besides, deep learning can be applied in market risk management, trading book risk management of banks, trading risk prediction etc. (Kim et al., 2019).

\section{Use of Al in Market Risk Management}

Market risk refers to changes in financial instruments' or contracts' values due to unpredicted fluctuations in asset prices, i.e., commodity prices, interest rates, foreign exchange rates and other market indices. In other words, market risk is the risk of portfolio's value fluctuations due to changes in price level or market price volatility (Bogojevic Arsic, 2009, p. 333). This suggests that every participant in financial market is exposed to market risk, directly or indirectly. Depending of the financial strength and the position size exposed to this risk, participants need to manage this risk. In this regard, financial institutions strive to manage this risk actively choosing the type of market risk to which they want to be exposed based on their knowledge about market prices' volatility. In contrast, nonfinancial companies seek for mitigating or, if possible, removing this risk together with other risk types (to mitigate market risk or to eliminate it along with other risk types). Al techniques can be helpful and their implementation in market risk management may lead to significant improvements. Machine learning as core Al technique can contribute to better market risk management the most.

The Financial Stability Board (2017) points out that market risk management has benefited from Al use in every stage of the process, i.e., from data preparation, to modelling, stress testing and model validation. The major contribution in data preparation gave machine learning techniques which proved their ability to deal with raw data taken from financial market and institutions or companies.

Machine learning techniques (such as decision trees, neural networks and deep leaning) showed that they can be used for cleaning the data, but also that they are able to, to some extent, overcome the missing or inaccurate data problem which is presented in papers of Garcýa-Laencina et al. (2007), Garcia-Laencina et al. (2008), Twala (2009), Ding and Simonoff (2010), Ghrobani and Zou (2018) and Wang et al. (2019).

Different machine learning techniques are also applied in classification which enabled more accurate data to be then used as inputs for model creation. This model includes also risk of using inadequate or incomplete or incorrect or, in some instances, risk of using the model that is no longer valid. In this regard, Al techniques (e.g., different machine learning techniques) can be used for market model stress testing for unintentional risk determination. In addition, model stress testing can be used in identification of risk which influences the trading behaviour and which can provide the benchmark or feedback mechanism for market risk decisions improvement or modification.

A number of financial institutions have tried to use machine learning for Value-at-Risk estimation and expected shortfall (Wilkens, 2019), but also to trading books because this has become a significant source of risk during the financial crisis in 2009 (such as PNP Paribas). Depending on model risk, source of risk and measurement of risk, the possible implementation of Al differs (Klein et al., 2015).

Abramov et al. (2017) gave an overview on how to run market risk model validation and how machine learning techniques should be used so that the market risk managers could make better decisions regarding market risk reduction and quantification of acceptable market risk level.

In one word, Al applications are inevitable because of their potential to lower the operating costs and provide more reliable data for financial risk management decision-making, which in turn enables financial institutions and companies, not only to survive, but to compete and grow.

\section{Use of Al in Credit Risk Management}

Credit risk is the risk of economic loss due to counterparty's inability to meet its contractual obligations. Accordingly, credit risk represents a risk of incurring loss because of borrower default or because of his credit quality reduction (Bogojevic Arsic, 2009, p. 439). The credit risk management represents a process of risk factors identification and analysis, measuring the risk level and selecting the appropriate measures of credit activities management in order to lower and/or to eliminate the credit risks. Over the past few 
decades a range of different statistical techniques have been used in credit risk management. But with the emergence of Fintech, those methods became insufficient and frequently not efficient enough in dealing with credit risk. Due to incompleteness of traditional techniques use in credit risk modelling, financial institutions started to use Al techniques for credit risk management enhancement.

Al techniques have shown better performance in credit risk modelling in comparison with traditional statistical techniques, but only their combination can improve accuracy (Altman et al., 1994). The most complex task is the credit risk assessment with Al techniques (such as machine learning). Al can help in credit event determination and cost of default estimation in the situations where credit risk occurs (Bogojevic Arsic, 2020).

Machine learning is used for enhanced lending decisions, both consumer and small and mediumsized enterprises lending. Decision trees and support vector machine application can provide significant cost savings (Khandani et al., 2010) and better credit risk modelling (Yao et al., 2015). The use of multivariate outlier detection machine learning techniques improved credit risk estimation in small and medium-sized enterprises lending (Figini et al., 2017). Besides, deep reinforcement learning method as a novel method for feature selection can be used for credit risk analysis improvement (Ha and Nguyen, 2016).

In addition, machine learning techniques helped lending-based crowdfunding development through improvement of credit scoring and credit rating profiles creation which helped the borrowers (especially, the startups and small companies) to get loans and lenders to have trust in the data presented and to be willing to extend the loans (Byanjankar et al., 2015) (Ha et al. 2019).

Finally, deep learning has proven its advantages in comparison with traditional techniques in credit default prediction and credit risk prediction both in traditional and alternative lending through lending platforms and credit (Son et al., 2016; Thang et al., 2019; Van-Sang et al., 2019; Hou, 2020).

\section{Use of Al in Operational Risk Management}

Operational risk is the risk of incurring loss due to physical decay, technical incompetence and human error in business operations of enterprises and institutions, including the fraud, unsuccessful management and process errors (Bogojevic Arsic, 2009, p. 530). However, this type of risk for each enterprise or institution has a different meaning because of their specifics (e.g., business portfolio structure, risk preferences etc.) that affect operating risk exposures. In this regards, Al can help enterprises and institutions in every stage of operational risk process (Sanford and Moosa, 2015).

A study conducted by the ORX Association, the largest operational risk association in the financial sector, showed that risk managers concluded that Al should be more included in operational risk management and that investing in Al tools application could provide running business in a more competitive, predictive, low costing, less risky and a more efficient way (Carrivick and Westphal, 2019).

Al can be useful in creating an adequate strategy of operational risk mitigation as well as in deciding whether to shift or to trade this risk and how to do this. The application of $\mathrm{Al}$ in operational risk management has to start from data preparation and classification and analysis of large data and the performances to prevent external losses).

The Al, and especially the machine learning, can contribute operational risk management through (Carrivick and Westphal, 2019):

- Reduction or elimination of time-consuming and repetitive tasks and process (e.g., some financial institutions managed to reduce the number of processes that needed to be reviewed),

- Deeper insight into data (to get valuable data),

- Easier decision-making process based on providing both wider and more concise information,

- Development of skilled employees and managers that communicate with regulators and

- Customers, and economy of scale through speed and accuracy throughout the organization.

The main areas where machine learning techniques can support operational risk management are: data quality assurance, text-mining for data augmentation and fraud detection (Carrivick and Westphal, 2019).

Machine learning can be helpful in collecting quality data by identifying duplicated data entries and extreme data values more accurately (e.g., to unsystematic or less probable risk identification). Application of 
machine learning may help to analyze the large amounts of data needed for risk management (e.g., internal and external loss data, internal risk indicators, macroeconomic data etc.) and to store and maintain data. In this way, different machine learning techniques can make a categorization of individual entries and augment the data. Finally, the most common use of machine learning is to detect the fraud and money laundering. The fraud is not easy to detect and is commonly done by financial transaction classification into suspicious and harmless. Machine learning can help by appropriate classification of these transactions as well as by reduction of false alarms where fraudulent transactions are overlooked. The common machine learning implementation is useful in preventing credit card fraud detection, but it can be also used for securities fraud detection (stock fraud, foreign exchange fraud, commodity pool fraud etc.).

\section{Challenge of Al in Financial Risk Management}

Evolution of $\mathrm{Al}$ in financial risk management is multidimensional and depends on many variables (nature of business, specific business lines, organizational structure, geography, regulations etc.).

Chartis research $(2019$, p.45) indicates that $\mathrm{Al}$ techniques have been mostly applied in retail banking, commercial banking and capital market financial risk management. In retail banking Al has used for modelling improvements and stress testing through supervised machine learning techniques and classification methods (such as support vector machine and decision trees). The further development of $\mathrm{Al}$ implementation will be toward behavioural models, scenario generation and behavioural and segmentation integration in asset pricing and portfolio optimization. Commercial banks represent a great challenge to $\mathrm{Al}$ application because of their relatively poor data management with big and complex documentation, not well structured data of benchmarks and credit curves. Some activities, such as passive strategies, need to be automated to some extent to ensure profitable operating. Besides, Al applications could be expected in scenario creation and testing, credit risk analytics and credit portfolio management. Lastly, in capital markets Al (i.e., different machine learning techniques) has been applied for database creation, yield curve and volatility surface anomaly detection and portfolio construction. In the near future more sophisticated and advanced Al applications can be expected in scenario creation, model validation, portfolio optimization and credit and equity risk modelling.

\section{Conclusion}

The further development of Fintech will continue to influence significantly the financial risk management. This influence will require further financial risk management transformation and change. In this regard, it could be expected that Al will become part of financial risk management framework of financial institutions and other participants in the financial market. This means that Al would provide automation and simplification in data management, improved stress testing and scenario generation and new methodology for dealing with complex, multivariable problems and non-linear optimization (Chartis research, 2019, p.48). In addition, wider application could be expected in equity-based and lendingbased crowdfundig through facilitation and acceleration of raising capital by equity issuance or loan approval to potential borrowers. Besides, Al can contribute to improving credit scoring of potential borrowers and creation of their credit rating which is essential for platforms' functioning as an intermediary in the crowdfunding process.

Based on the above, it follows that there are no barriers to Al techniques application in financial risk management. The application of these techniques will deliver accurate real-time information on financial risk types to which institutions and companies are exposed and which need to be managed in an advanced manner. Namely, efficient and improved financial risk management will combine traditional statistical techniques with Al techniques, such as deep learning, artificial neural networks and advanced classification methods.

\section{Acknowledgments}

Parts of this text have been presented at the XVII International Symposium Symorg 2020 - "Business and Artificial Intelligence". The paper, as best presented in the session "Transformation of financial servieces", has been recommended for further extension and review in the Management: Journal of Sustainable Business and Management Solutions in Emerging Economies. 


\section{REFERENCES}

[1] Abedin, M. Z., Guotai, C., Colombage, S \& E-Moula, F. (2018). Credit default prediction using a support vector machine and a probabilistic neural network. Journal of Credit Risk, 14(2). 1-29. Retrieved from: https://www.risk.net/journal-of-credit-risk/5568901/credit-default-prediction-using-a-support-vector-machineand-a-probabilistic-neural-network

[2] Abramov, V., Lowdermik, M. \& Zhou, X. (2017). A Practical guide to market risk model validations (Part I Introduction). DOI: 10.2139/ssrn.2916853

[3] Altman, E. I., Marco, G. \& Varetto, F. (1994). Corporate distress diagnosis: Comparisons using linear discriminant analysis and neural networks (the Italian experience). Journal of Banking \& Finance, 18(3), 505529, DOI: 10.1016/0378-4266(94)90007-8

[4] Bogojevic Arsic, V. (2009). Upravljanje finansijskim rizikom. SZR „Kragulj“. Beograd.

[5] Bogojevic Arsic, V. (2020). Challenges of financial risk management: Al applications, XVII International Symposium Symorg 2020 - "Business and Artificial Intelligence". 7 - September 2020 online.

[6] Byanjankar, A., Heikkila, M. \& Mezei, J., (2015), Predicting credit risk in peer-to-peer lending: A Neural network approach. 2015 IEEE Symposium Series on Computational Intelligence. DOI: 10.1109/SSCI.2015.109

[7] Carrivick, L. \& Westphal, A. (2019). Machine learning in operational risk-making a business case for its practical implementation. White paper. ORX Association. Retrieved from: https://managingrisktogether.orx.org/sites/default/files/public/downloads/2019/09/orxthecaseformachinelea rninginoperationalriskwhitepaper.pdf

[8] Chartis research. (2019). State of Al in Risk Management: Developing an Al roadmap for risk and compliance in the finance industry. Digital Services Limited \& Tata Consultancy Services. Retrieved from: https://www.chartis-research.com/technology/artificial-intelligence-ai/state-ai-risk-management-10976.

[9] Chen, L., Pelger, M. \& Zhu, J. (2019). Deep learning in asset pricing. DOI: 10.2139/ssrn.3350138

[10] Day, S. (2017). Quants turn to machine learning to model market impact. Risk.net. Retrieved from: https://www.risk.net/asset-management/4644191/quants-turn-to-machine-learning-to-model-marketimpact.

[11] Ding, Y. \& Simonoff, J.S. (2010). Investigation of missing data methods for classification trees applied to binary response data. Journal of Machine Learning Research, 11, 131-170. Retrieved from: http://www.jmlr.org/papers/volume11/ding10a/ding10a.pdf

[12] Figini, S., Bonelli, F. \& Giovannini, E. (2017). Solvency prediction for small and medium enterprises in banking. Decision Support Systems. 102, 91-97. DOI: 10.1016/j.dss.2017.08.001

[13] Financial Stability Board. (2017). Artificial intelligence and machine learning in financial services. Retrieved from: http://www.fsb.org/wp-content/uploads/ P011117.pdf

[14] Garcia-Laencina, P.J., Serrano, J., Figueiras-Vidal, A.R. \& Sancho-Goomez, J.L. (2007). Multi-task neural networks for dealing with missing inputs, Conference on the Interplay Between Natural and Artificial Computation, IWINAC. DOI: 10.1007/978-3-540-73053-8 28

[15] Garcia-Laencina, P.J., Sancho-Goomez, J.L. \& Figueiras-Vidal, A.R. (2008). Machine learning techniques for solving classification problems with missing input data, 12th World Multi-Conference on Systemics. Cybernetics and Informatics. Retrieved from: https://www.researchgate.net/publication/257207095

[16] Ghrobani, A. \& Zou J. Y. (2018). Embedding for informative missingness: deep learning with incomplete data. 56th Annual Allerton Conference on Communication, Control, and Computing. DOI: 10.1109/ALLERTON.2018.8636008

[17] Hamdy, A. \& Hussein, B.W. (2016). Credit risk assessment model based using principal component analysis and artificial neural network. MATEC Web of Conferences 76, 02039, CSCC 2016. DOI: 10.1051/matecconf/20167602039

[18] Ha, V., Lu, D., Choi, G. S., Nguyen, H. \& Yoon, B. (2019), Improving credit risk Prediction in online peerto-peer (P2P) lending using feature selection with deep learning. 21st International Conference on Advanced Communication Technology (ICACT), 511-515. DOI:10.23919/ICACT.2019.8701943

[19] Ha, V.S. \& Nguyen, H.N. (2016) Credit scoring with a feature selection approach based deep learning. MATEC Web of Conferences 54, DOI: 10.1051/matecconf/20165405004

[20] Harris, T. (2015). Credit scoring using the clustered support vector machine. Expert Systems with Applications, 42(2), 741-750. DOI: 10.1016/j.eswa.2014.08.029

[21] Heaton, J. B., Polson, N. G., \& Witte, J. H. (2017). Deep learning for finance: Deep portfolios. Applied Stochastic Models in Business and Industry, 33(1), 3-12.

[22] Hou, X. (2020). P2P borrower default identification and prediction based on RFE-multiple classification models. Open Journal of Business and Management, 8(2), 866-880. DOI: 10.4236/ojbm.2020.82053

[23] Kim, A., Yang, Y., Lessmann, S., Ma, T., Sung, M. C. \& Johnson J. E.V. (2019). Can deep learning predict risky retail investors? A case study in financial risk behaviour forecasting. European Journal of Operational Research, 283(1), 217-234. DOI: 10.1016/j.ejor.2019.11.007

[24] Khandani, A. E., Kim, A. J., \& Lo, A. W. (2010). Consumer credit risk models via machine learning algorithms. Journal of Banking \& Finance, 34(11), 2767-2787. DOI: 10.1016/j.jbankfin.2010.06.001

[25] Klein, L., Jacobs, M. \& Merchant, A. (2015). Emerging trends in model risk management: High performance delivered. Retrieved from: https://www.accenture.com/_acnmedia/Accenture/Conversion- 
Assets/DotCom/Documents/Global/PDF/Industries_19/Accenture-Emerging-Trends-Model-RiskManagement.pdf

[26] Lean, Y. (2014). Credit Risk Evaluation with a Least Squares Fuzzy Support Vector Machines Classifier, Discrete Dynamics in Nature and Society, 1, 1-9. DOI: 10.1155/2014/564213

[27] Nazemi, A., Heidenreich, K., \& Fabozzi, F. J. (2018). Improving corporate bond recovery rate prediction using multifactor support vector regressions. European Journal of Operational Research, 271(2), 664-675. DOI: 10.1016/j.ejor.2018.05.024

[28] Pacelli, V. \& Azzollini, M. (2011). An Artificial neural network approach for credit risk management. Journal of Intelligent Learning Systems and Applications, 3, 103-112. DOI: 10.4236/jilsa.2011.32012.

[29] Radovic, O. \& Stankovic, J. (2015). Tail Risk Assessment Using Support Vector Machine, Journal of Engineering Science and Technology Review, 8(1), 61-64. DOI: 10.25103/jestr.081.11

[30] Regan, S., Klein, L., Jacobs, M. \& Kazmi, S. (2017). Model behavior nothing artificial - Emerging trends in the validation of machine learning and artificial intelligence models. Accenture consulting. Retrieved from: ht t ps://www. accenture.com/_acnmedia/accenture/conversion assets/mainpages/documents/global/accenture-emerging-trends-in-the-validation-of-ml-and-ai-models.pdf

[31] Sanford, A., \& Moosa, I. (2015). Operational risk modelling and organizational learning in structured finance operations: A Bayesian network approach. Journal of the Operational Research Society, 66(1), 86115.

[32] Son, Y., Byun, H., \& Lee, J. (2016). Nonparametric machine learning models for predicting the credit default swaps: An empirical study. Expert Systems with Applications, 58, 210-220. DOI: 10.1016/j.eswa.2016.03.049

[33] Tang, L., Fei Caib, F. \& Ouyanga, Y. (2019). Applying a nonparametric random forest algorithm to assess the credit risk of the energy industry in China. Technological Forecasting \& Social Change. 144, 563-572. DOI: 10.1016/j.techfore.2018.03.007

[34] Twala, B. (2009). An Empirical comparison of techniques for handling incomplete data using decision trees. Applied Artificial Intelligence, 23(5), 373-405. DOI: 10.1080/08839510902872223

[35] van Liebergen, B. (2017). Machine learning: A revolution in risk management and compliance? Journal of Financial Transformation, 45, 60-67. Retrieved from: https://capco.com/Capco-Institute/Journal-45Transformation/Machine-learning-a-revolution-in-risk-management-and-compliance

[36] Van-Sang, H., Dang, N.L., Gyoo, S.C., Ha, N.N. \& Yoon, B. (2019). Improving Credit Risk Prediction in Online Peer-to-Peer (P2P) Lending Using Feature selection with Deep learning, 21st International Conference on Advanced Communication Technology (ICACT). DOI: 10.23919/ICACT.2019.8701943

[37] Wang, J. \& Wang, J. (2015). Forecasting stock market indexes using principle component analysis and stochastic time effective neural networks, Neurocomputing. 156, 68-78. DOI: 10.1016/j.neucom.2014.12.084

[38] Wang S., Li B., Yang M. \& Yan Z. (2019). Missing Data Imputation for Machine Learning. In: Li B., Yang M., Yuan H. \& Yan Z. (Eds) loT as a Service. Springer.

[39] Wilkens, S. (2019). Machine Learning in Risk Measurement: Gaussian Process Regression for Value-atRisk and Expected Shortfall. Journal of Risk Management in Financial Institutions. 12, 374-383. DOI: 10.2139/ssrn.3246131 Retrieved from: SSRN: https://ssrn.com/abstract=3246131

[40] Yao, X., Crook, J. \& Andreeva, G. (2015). Support Vector Regression for Loss Given Default Modelling. European Journal of Operational Research. 240, 528-538. DOI:10.1016/j.ejor.2014.06.043.

Received: 2020-12-06

Revisions requested: 2021-01-11

Revised: 2021-02-18

Accepted: 2021-03-16

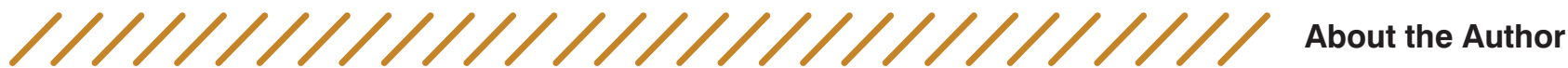

\section{Vesna Bogojević Arsić \\ University of Belgrade, Faculty of Organizational Sciences, Serbia vesna.bogojevic.arsic@fon.bg.ac.rs}

Vesna Bogojević Arsić, PhD, is a full professor of financial markets, corporate finance and financial risk management at the Department of Financial management and accounting, Faculty of Organizational Sciences, University of Belgrade. Her research interests and fields are related to corporate finance and restructuring, financial markets, financial risk management, portfolio management and financial engineering. The author has published 7 books and over 100 scientific papers in journals and conference proceedings in international and national journals and conferences.

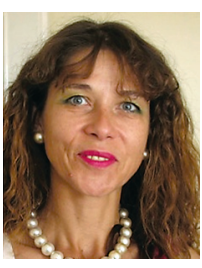

